\title{
Impact of COVID-19 on New Mexico Harm Reduction Services: Challenges and Recommendations
}

\author{
Anita Reta \\ University of New Mexico \\ Leah Nelson \\ University of New Mexico \\ Rachel Rose \\ University of New Mexico \\ Valerie Carrejo \\ University of New Mexico
}

Snehal Bhatt ( $\nabla$ sbhatt@salud.unm.edu )

Department of Psychiatry and Behavioral Sciences, University of New Mexico MSC095030 https://orcid.org/0000-0003-0004-7987

\section{Research}

Keywords: substance use disorders (SUD), harm reduction (HR), medication assisted treatment (MAT) clinics

Posted Date: January 5th, 2021

DOI: https://doi.org/10.21203/rs.3.rs-139091/v1

License: (c) (i) This work is licensed under a Creative Commons Attribution 4.0 International License. Read Full License 


\section{Abstract}

Evidence is emerging indicating persons with substance use disorders (SUD) are at particular risk of adverse health outcomes during the Sars-CoV2 pandemic crisis, especially compounded if those persons are underrepresented minorities. New Mexico has unique demographic characteristics being predominantly rural and minority populated. We attempted to survey harm reduction (HR) sites across the state to understand and document the effects the current health crisis has had on their operations. Sites reported a significant decrease $(p=0.05)$ in clients served between the time periods of November 2019January 2020 and March-May 2020, supply shortages, and anecdotal reports of increasing street drug prices. Future research should focus on rates of overdose during public health crises, its effects on medication assisted treatment (MAT) clinics, and in continued efforts to curtail rates of SUD overall.

\section{Highlights}

- New Mexico, a predominantly rural state, has fifty Harm Reduction sites that were affected by the March stay-at-home orders, causing at least two sites to discontinue services completely.

- Maintaining stock of necessary supplies, especially syringes, was the most cited hardship.

- Harm reduction sites saw a significant decrease in clients served during the March 2020 stay-athome orders.

- Most sites reported anecdotal evidence from clients of increased street prices of illicit substances.

\section{Background}

New Mexico, a sparsely populated minority-majority state in the southwestern United States, has consistently placed at the bottom of most population health scales (NM IBIS, 2018.). Among its many challenges, the state has high rates of opioid, alcohol and methamphetamine use disorders, extreme rurality, and very limited healthcare infrastructure (NM IBIS, 2018-2019.). Opioid-related deaths have been endemic in New Mexico dating back to 1999 and is considered a multi-generation problem in some areas of the state (NIDA 2020., Nmhealth, 2020., Garcia, 2010.). Recent data demonstrate that overall, New Mexico has approximately 24 opioid overdose deaths per 100,000, with several counties having rates of 40-90 per 100,000 (NM IBIS, 2019.). In a survey of New Mexico residents done by the New Mexico Department of Health (NMDOH), $63 \%$ of respondents indicated they knew someone who "is or has been addicted to opioids" (NMDOH, 2019). With such high prevalence of opioid use disorder (OUD) and related deaths, the NMDOH became a leader in Harm Reduction (HR), with a state-operated syringe exchange program started in 1997 (NMSA 1978 24-2C Harm Reduction Act). HR sites are defined as organizations that provide syringe exchange, overdose prevention, and/or HIV/STI testing for communities impacted by substance use disorders (SUD) with a primary goal to reduce the adverse health, social, or economic consequences of drug use without necessarily reducing drug consumption (Principles, 2019.). HR programs are an effective way of reducing injection-related HIV and hepatitis $C$ infections, syringes discarded in public areas, and overdose deaths (organize references) (Irwin, et al. 2017.; Greenburg, 2019.; 
Wood, et al. 2006.; Saloner, et al., 2018.; Aspinall, et al., 2013.). According to the NMDOH, New Mexico currently accounts for $7-8 \%$ of all syringe services in the United States, with a $50 \%$ increase in syringe service program enrollments since 2012. Current HR services offered in New Mexico include, but are not limited to, syringe services, overdose prevention training, naloxone distribution, social services referrals, primary medical care referrals etc. In New Mexico, there are 12 state-contracted HR sites and 38 Public Health Offices that provide HR services; these sites are especially crucial to fighting the opioid epidemic in rural areas (NMDOH).

SARS-CoV-2 arrived in New Mexico on March 11th, 2020 with four travelers returning from international vacations. Given the poor baseline health of the state's population, unequal distribution of hospital beds, and limited infrastructure for intensive care surge capacity, the state government recognized the potential for catastrophe and moved quickly to prevent spread of the virus. On March 23rd, New Mexico Governor Michelle Lujan Grisham announced a statewide 'stay-at-home' order. The order required that all schools, universities, and non-essential businesses in the state close, and that people leave their homes only for outings "necessary for their health, safety, or welfare" (CABQ, 2020.). Harm reduction sites were allowed to stay open as they were deemed essential in alignment with the American Medical Association's (AMA) position statement recommending that syringe exchange and naloxone distribution be maintained and prioritized during such closures (AMA, 2020). Medical practices in the state were referred to the Center for Disease Control (CDC) guidance for COVID-safe practice changes. The CDC guidelines recommended maximization of telehealth services; limiting number of visitors and daily appointments; physical distancing of six feet or more; increased screening and sanitizing practices; and visual aids indicating the new guidelines and encouraging hand hygiene (CDC, 2020).

Despite the lock-down, by mid-April, McKinley and San Juan counties became a national virus hotspot with per-capita infection and death rates comparable to and eventually surpassing New York City (Silverman, 2020). The Native American communities in these counties, particularly individuals from the Navajo Nation, were especially hard-hit with 8,837 confirmed cases and 434 deaths in July (Navajo Nation DOH, 2020). The SARS-CoV-2 pandemic has been especially harmful for individuals from minority groups, with minority death rates over two-fold higher than for white individuals reported in many states (Kaur, 2020; Dorn, et al. 2020). Similarly, the virus appears to be especially harmful for those with SUD. Preliminary research findings have demonstrated high infection rates and mortality among people with SUD (Wei, et al. 2020). Given that New Mexico has large numbers of people using HR services particularly in rural and minority populated areas, we wished to investigate the impact of the pandemic on HR. Our study uses cross-sectional survey methods to investigate the impact of the SARS-CoV-2 pandemic on HR services in New Mexico.

\section{Methods}

\subsection{Materials}

Survey Design: 
The survey questionnaire was developed by the researchers of this project. The survey was designed to measure the degree to which HR sites have been impacted by the SARS-CoV-2 pandemic. The survey questionnaire included a total of thirty questions, with additional branching/follow-up questions for specific answers. Rural versus metropolitan metro sites were determined by self-reporting rural or urban areas served. See Appendix A for the complete list of questionnaire items.

\subsection{Participants}

\section{Recruitment/ Study Population and Sampling:}

A list of all operating HR sites in the state of New Mexico were provided by the $\mathrm{NMDOH}$. Sites designated as exclusively syringe drop off boxes were excluded. A total of fifty HR sites were identified: twelve sites were independently operated and contracted with the state, and 38 sites were associated with $\mathrm{NMDOH}$ public health offices. Each of the fifty HR sites were emailed a request for participation, provided informed consent documentation and a URL to the REDCap survey questionnaire. Responses were submitted and collected through the REDCap database system.

\subsection{Procedure}

\subsubsection{Data collection:}

One survey was administered per HR site, to be filled out by one designated employee of the site's choice. Participants were told the survey was designed to better understand how stay-at-home orders and the SARS-CoV-2 pandemic are impacting the provision of HR services in the state of New Mexico. A consent form was sent with the survey link, outlining the benefits and risks of participating in the study. After reading the consent, participants had the choice to participate by clicking the survey link or declining participation. Participants generally completed the questionnaire within thirty minutes, were thanked for their participation, and were dismissed. No financial or other tokens of gratitude were provided for survey completion.

\subsubsection{Data analysis and availability:}

Data was collected into RedCap and simple summary statistics were completed using Microsoft Excel version 16.38. Data distribution analysis revealed skewing for most site characteristic data. Chi-square tests were used for multiple comparisons of the categorical data. The datasets generated during and/or analysed during the current study are available from the corresponding author on reasonable request.

\subsubsection{Study Limitations:}

As with all survey data collection, self-report and recall bias were limitations to these methods. Additionally, asking participants to recall information from prior months may lead to inaccuracy of certain data points. 


\section{Results}

A total of 12 independently operated $\mathrm{HR}$ sites and the $\mathrm{NMDOH}$ were invited to participate in this study. The NMDOH operates 38 sites throughout the state and elected to have a single respondent complete the survey providing an average for the 38 sites. Of the 13 total surveys sent there was a $100 \%$ response rate, representing $50 \mathrm{HR}$ sites across the state. Characteristics of the sites in the three months prior to and during the SARS-CoV-2 pandemic response in New Mexico are shown in Table 1. In the three months prior to the Governor's stay-at-home order issued on 12 March 2020, the majority of sites reported an average of over 51 clients per week (44/50, 88\%), had 4-5 staff/volunteers on site (43/50, 86\%), were open 5 days per week (48/50 96\%), and served a rural area (42/50, 84\%). Prior to the pandemic, seven sites offered street or van outreach $(7 / 50,14 \%)$.

After the stay-at home order was issued, most HR sites continued to provide services at levels nearly comparable to pre-pandemic operations (Table 1), with the exception of two independently-operated sites that discontinued HR services entirely $(2 / 50,4 \%)$. Both of these closed sites provided street outreach. One additional site stayed open at one location, but discontinued van or street outreach programs for a total of $3 / 50(6 \%)$ of sites stopped mobile services. For the 48 sites that remained open, most continued to operate at similar levels of clients and staffing with the majority of sites continuing to serve over 51 clients per week (43/48, 90\%), 4-5 staff/volunteers on site (41/48, $85 \%)$, and open 5 days per week $(47 / 48,98 \%)$.

Table 2 shows the service changes reported by HR sites in response to the SARS-CoV-2 pandemic. Some respondents from independent HR sites noted reduction in HR service hours (4/10,40\%). Most independent sites, those not operated by the $\mathrm{DOH}$, reported a decrease in their monthly budget after the start of the pandemic $(5 / 10,50 \%)$. While operations continued, most sites reported scarcity in supplies with syringes, tourniquets, and biohazard containers all in short supply $(8 / 10,80 \%)$. In comment boxes provided in the survey, some sites noted that they had to limit the number of syringes exchanged per client and others noted that HR services had been moved outdoors to limit the number of people entering their facility. For sites that remained open, the distribution of naloxone kits and fentanyl test strips remained nearly constant despite the pandemic. Most independent HR sites reported that they had to reduce services during the pandemic (5/10,50\%). Reduced services included HIV and HCV testing, group sessions, clinical procedures, and street outreach. While many sites reduced services, some were also able to add new services during the pandemic $(6 / 10,60 \%)$. Some of the new services noted were the provision of masks, gloves, hand hygiene supplies, expansion of social services (e.g. food), and telemedicine expansion for buprenorphine patients.

The most commonly reported infection control measures at all open HR sites including the DOH-operated sites were physical distancing requirements (48/48, 100\%), increased sanitation (47/48, $98 \%$ of sites), and new PPE requirements for staff (46/48, 96\%). Most sites also reported using symptom screening $(41 / 48,85 \%)$ and temperature screening $(41 / 48,85 \%)$ for staff/volunteers. The least common infection control measure was temperature screening of clients, which was only performed by 3 of 48 sites (6\%). 
Subjective questions were included in the survey to attempt to understand how the stay-at-home order and pandemic had altered the HR community experiences (Table 3). The data from the NMDOH sites was considered as a single respondent for the subjective analysis. Only 2 of the 13 respondents reported awareness of any clients who tested positive for SARS-CoV-2. A few responded that clients had reported street drug scarcity $(2 / 13,15 \%)$ and price increases $(3 / 13,26 \%)$ due to the pandemic, as well as increased incidence of opioid and alcohol withdrawal (each with 1 of 13 respondents, $8 \%$ ). Only one respondent reported an increase in drug overdose deaths (8\%).

\section{Discussion}

Due to the implementation of SARS-CoV-2 policies and precautions, especially social distancing, patients with SUD are at an increased vulnerability to adverse outcomes related to substance use (Douglas, et al. 2020). Increased isolation worsens comorbid mental health disorders and symptoms, increasing the risk of use and overdose (Schimmel, et al. 2020). Further, social isolation creates an environment in which people are more likely to use alone, without a partner monitoring them.

In addition to the risk of social isolation and misuse, underrepresented minority (URM) populations in the state of New Mexico are already disproportionately separated from resources. Prior to and during the pandemic, individuals living in rural communities are wrought with food insecurity and difficulty accessing healthcare services (USDA, 2019.; NM IBIS, 2019). With the forced changes in healthcare practices posed by SARS-CoV-2 and high rates of poverty throughout the state, those in rural communities have experienced an even greater lack of access to care (NM-IBIS 2019; Romero, 2020).

The circumstances surrounding social isolation and lack of access to care, superimposed upon PPE shortages and budgetary shortages, pose unique challenges to HR operations during a global pandemic. When considering the impact SARS-CoV-2 has on New Mexico's communities, it is crucial to consider how operations like HR have been affected, making New Mexico's most vulnerable and isolated populations more susceptible to adverse outcomes.

Limitations to this study include a small sample size of 13 respondents representative of fifty sites. The average of thirty eight public health offices may have under or overestimated individual outcomes. The categorical survey questions created upper limits of data, and may have underestimated data, for example if a site had much higher than 51 clients, we were unable to demonstrate those nuances. Because of the unique demographics of New Mexico, these results may not be generalizable to other HR operations around the country. Lastly, each respondent was chosen within the HR site which may have negatively impacted the accuracy of data given in each survey.

Harm Reduction services are crucial in mitigating the personal and communal negative effects associated with SUD in the community, and are even more crucial in saving lives during times of increased stress (Greenberg, 2019). In order for HR service to function during times of public crisis and continue to serve our vulnerable communities struggling with SUD, there must be prior planning and preparation for such crises. As recommended by multiple agencies, stockpiling of PPE and other medical 
supplies should be adequate and maintained to address pandemic crises-in the case of HR sites, syringes especially should be stockpiled as this was the most commonly cited equipment shortage (Hashikuro \& Kizu, 2009; Carias, et al. 2015). Further, a decrease in the overall burden to HR sites, i.e. decreasing the number of patients in need of such services, can reduce the impact pandemic and associated shortages have on the delivery of such essential services. Policies focused on increased funding for medication assisted treatment (MAT) clinics and the implementation of evidence-based interventions such as safe-injection sites can help communities become less dependent on harm reduction, decrease healthcare costs associated with SUD and comorbidities, and decrease the negative public health impacts on society (Irwin, et al. 2017; Wood, et al. 2006). This could be especially beneficial for New Mexico as increased funding could expand the reach of HR and MAT to our most remote areas.

More data should be collected to document the extent of effect stay at home orders and other Sars-CoV2 policies have had on patients with SUD. Research surveying MAT clinics and data collection from Emergency Departments may provide a more complete understanding of these effects and can guide further recommendations.

\section{Conclusion}

Harm Reduction sites provide essential, life-saving services to people struggling with substance use disorders while simultaneously decreasing adverse community effects of widespread substance use. During health crises, it is necessary to consider the preparedness of local infrastructures to not only support traditional healthcare operations but also extend to public health interventions serving vulnerable populations. New Mexico in particular, with high rates of OUD, alcoholism and rising hepatitis $C$ infections in the context of extreme rurality and poverty, would benefit from policy supporting further protection and subsidy.

\section{Declarations}

\subsection{Ethics Approval and Consent to Participate:}

Ethics Approval Not Applicable.

The study did use a consent form, which was sent with the survey link, outlining the benefits and risks of participating in the study. After reading the consent, participants had the choice to participate by clicking the survey link or declining participation [Please see attached].

\subsection{Consent for Publication:}

Not applicable.

\subsection{Availability of Data and Materials:}


The datasets generated during and/or analysed during the current study are available from the corresponding author on reasonable request.

\subsection{Competing Interests:}

The authors declare that they have no competing interests.

\subsection{Funding:}

Not applicable.

\subsection{Authors Contributions:}

AR: Conceptualization, Methodology, Formal analysis, Data curation, Writing - Original Draft. LN: Formal analysis, Data Curation, Writing - Review \& Editing. RR: Data Curation, Writing - Review \& Editing. VC: Supervision, Writing - Review \& Editing. SB: Conceptualization, Methodology, Writing - Review \& Editing, Supervision, Submission.

All authors read and approved the final manuscript.

\subsection{Acknowledgements:}

Not applicable.

\section{References}

1. New Mexico Department of Health (2018, November 29). Health Indicator Report of General Health Status. Retrieved June 30, 2020, from https://ibis.health.state.nm.us/indicator/view/GenHIth.Year.NM_US.html

2. New Mexico Department of Health (2019). Health Indicator Report of Alcohol - Alcohol-Related Death. Retrieved June 30, 2020, from https://ibis.health.state.nm.us/indicator/view/AlcoholRelatedDth.Year.NM_US.html

3. New Mexico Department of Health (2018). Health Indicator Report of Tobacco Use - Adult Smoking Prevalence. Retrieved July 12, 2020, from https://ibis.health.state.nm.us/indicator/view/TobaccoSmokeAdult.Year.NM_US.html

4. New Mexico Department of Health (2019). Health Indicator Report of Health Care Access - Primary Care Physicians Compared to Population Size. Retrieved July 12, 2020, from https://ibis.health.state.nm.us/indicator/view/HlthCarePriCareProviders.Cnty.html

5. National Institute on Drug Abuse. (2020, July 02). New Mexico: Opioid-Involved Deaths and Related Harms. Retrieved August 5, 2020, from https://www.drugabuse.gov/drug-topics/opioids/opioidsummaries-by-state/new-mexico-opioid-involved-deaths-related-harms 
6. New Mexico Department of Health. 2020. Nearly Two Out Of Three New Mexicans Know Someone Addicted To Opioids. [online] Available at: <https://nmhealth.org/news/information/2019/4/? view $=758>$ [Accessed 24 April 2020].

7. Garcia, A. (2010). The pastoral clinic: Addiction and dispossession along the Rio Grande. Berkeley: University of California Press.

8. New Mexico Department of Health (2019). Health Indicator Report of Drug Overdose Deaths. Retrieved July 30, 2020, from https://ibis.health.state.nm.us/indicator/view/DrugOverdoseDth.Year.NM_US.html

9. Principles of Harm Reduction. (1995). Retrieved June 19, 2020, from https://harmreduction.org/about-us/principles-of-harm-reduction/

10. Irwin, A., Jozaghi, E., Weir, B., Allen, S., Lindsay, A. and Sherman, S., 2017. Mitigating the heroin crisis in Baltimore, MD, USA: a cost-benefit analysis of a hypothetical supervised injection facility. Harm Reduction Journal, 14(1).

11. Greenberg, M., 2019. The value of harm reduction for injection drug use: A clinical and public health ethics analysis. Disease-a-Month, 65(5), p.118.

12. Wood, E., Tyndall, M., Montaner, J. and Kerr, T., 2006. Summary of findings from the evaluation of a pilot medically supervised safer injecting facility. Canadian Medical Association Journal, 175(11), pp.1399-1404.

13. Saloner, B., Mcginty, E. E., Beletsky, L., Bluthenthal, R., Beyrer, C., Botticelli, M., \& Sherman, S. G. (2018). A Public Health Strategy for the Opioid Crisis. Public Health Reports, 133(1_suppl). doi:10.1177/0033354918793627

14. Aspinall, E. J., Nambiar, D., Goldberg, D. J., Hickman, M., Weir, A., Velzen, E. V., . . Hutchinson, S. J. (2013). Are needle and syringe programmes associated with a reduction in HIV transmission among people who inject drugs: A systematic review and meta-analysis. International Journal of Epidemiology,43(1), 235-248. doi:10.1093/ije/dyt243

15. City of Albuquerque. (2020). New Mexico COVID-19 Timeline. Retrieved June 15, 2020, from https://coronavirus-response-albuquerquecabq.hub.arcgis.com/app/daf807a2617242d9ba6bbcb4f81262d0

16. American Medical Association. 2020. COVID-19 policy recommendations for OUD, pain, harm reduction. Retrieved June 15, 2020, from https://www.ama-assn.org/delivering-care/publichealth/covid-19-policy-recommendations-oud-pain-harm-reduction

17. Center for Disease Control. (2020). Healthcare Facilities: Managing Operations During the COVID-19 Pandemic. Retrieved June 15, 2020, from https://www.cdc.gov/coronavirus/2019ncov/hcp/guidance-hcf.html

18. Silverman, H., Toropin, K., \& Sidner, S. (2020, May 18). Navajo Nation surpasses New York state for the highest Covid-19 infection rate in the US. Retrieved June 15, 2020, from https://www.cnn.com/2020/05/18/us/navajo-nation-infection-rate-trnd/index.html 
19. Navajo Nation Department of Health. (2020). Dikos Ntsaaígíi-19 (COVID-19) . Retrieved July 30, 2020, from https://www.ndoh.navajo-nsn.gov/COVID-19

20. Kaur, H. (2020, May 09). The coronavirus pandemic is hitting black and brown Americans especially hard on all fronts. Retrieved July 30, 2020, from https://www.cnn.com/2020/05/08/us/coronaviruspandemic-race-impact-trnd/index.html

21. Dorn, A. V., Cooney, R. E., \& Sabin, M. L. (2020). COVID-19 exacerbating inequalities in the US. The Lancet, 395(10232), 1243-1244. doi: 10.1016/s0140-6736(20)30893-x

22. Wei, Y., \& Shah, R. (2020). Substance Use Disorder in the COVID-19 Pandemic: A Systematic Review of Vulnerabilities and Complications. Pharmaceuticals, 13(7), 155. doi:10.3390/ph13070155

23. Douglas, M., Katikireddi, S. V., Taulbut, M., Mckee, M., \& Mccartney, G. (2020). Mitigating the wider health effects of covid-19 pandemic response. Bmj, M1557. doi:10.1136/bmj.m1557

24. Schimmel, J., \& Manini, A. F. (2020). Opioid Use Disorder and COVID-19: Biological Plausibility for Worsened Outcomes. Substance Use \& Misuse,55(11), 1900-1901. doi:10.1080/10826084.2020.1791184

25. US Department of Agriculture. (2019). Food Security in the United States: How Do States Compare? Retrieved July 30, 2020, from https://www.ers.usda.gov/topics/food-nutrition-assistance/foodsecurity-in-the-us/interactive-charts-and-highlights/

26. New Mexico Department of Health. (2019). Health Indicator Report of New Mexico Population Poverty Among All Persons. Retrieved June 30, 2020, from https://ibis.health.state.nm.us/indicator/view/NMPopDemoPov.Cnty.html

27. Romero, S. (2020, May 04). New Mexico Invokes Riot Law to Control Virus Near Navajo Nation. Retrieved June 30, 2020, from https://www.nytimes.com/2020/05/04/us/coronavirus-new-mexicogallup-navajo.html

28. Greenberg, M., 2019. The value of harm reduction for injection drug use: A clinical and public health ethics analysis. Disease-a-Month, 65(5), p.118.

29. Hashikura, M., \& Kizu, J. (2009). Stockpile of personal protective equipment in hospital settings: Preparedness for influenza pandemics. American Journal of Infection Control,37(9), 703-707. doi:10.1016/j.ajic.2009.05.002

30. Carias, C., Rainisch, G., Shankar, M., Adhikari, B. B., Swerdlow, D. L., Bower, W. A., . . Koonin, L. M. (2015). Potential Demand for Respirators and Surgical Masks During a Hypothetical Influenza Pandemic in the United States. Clinical Infectious Diseases,60(Suppl_1). doi:10.1093/cid/civ141

31. Irwin, A., Jozaghi, E., Weir, B., Allen, S., Lindsay, A. and Sherman, S., 2017. Mitigating the heroin crisis in Baltimore, MD, USA: a cost-benefit analysis of a hypothetical supervised injection facility. Harm Reduction Journal, 14(1).

32. Wood, E., Tyndall, M., Montaner, J. and Kerr, T., 2006. Summary of findings from the evaluation of a pilot medically supervised safer injecting facility. Canadian Medical Association Journal, 175(11), pp.1399-1404. 


\section{Tables}

Table 1: Characteristics of clients and staffing of HR sites pre- and intra- the SARS-CoV-2 pandemic

\begin{tabular}{|c|c|c|c|}
\hline- & Nov 2019 - Jan 2020 & March-May 2020 & p-value \\
\hline Open HR Sites & $\underline{50}$ & $\underline{48}$ & - \\
\hline Clients Served Per Week & - & - & \multirow[t]{4}{*}{$\underline{0.05}$} \\
\hline$>=51$ & $\underline{44}$ (8%). & 43 (90\%). & \\
\hline$\underline{21-50}$ & $\underline{5}(\underline{10 \%})$. & $\underline{2}(\underline{4 \%})$. & \\
\hline$\underline{1-20}$ & $1(\underline{2 \%})$. & $\underline{3}(\underline{6 \%})$. & \\
\hline$\underline{\text { Staff Per Week }}$ & - & - & \multirow[t]{5}{*}{$\underline{0.66}$} \\
\hline$>=11$ & $\underline{1(\underline{2 \%})}$. & $\underline{0}(\underline{0 \%})$. & \\
\hline$\underline{6-10}$ & $\underline{2}(\underline{4 \%})$. & $\underline{3}(\underline{6 \%})$. & \\
\hline$\underline{4-5}$ & $\underline{43}(\underline{86 \%})$. & $\underline{41}(\underline{85 \%})$. & \\
\hline$\underline{1-3}$ & $\underline{4}(\underline{8 \%})$. & $\underline{4}(\underline{8 \%})$. & \\
\hline Days Per Week & - & - & \multirow[t]{4}{*}{$\underline{0.60}$} \\
\hline$\underline{5}$ & $\underline{48}(\underline{96 \%})$. & $\underline{47}(\underline{98 \%})$. & \\
\hline$\underline{4}$ & 1 (2\%). & $\underline{0}(\underline{0 \%})$. & \\
\hline$\underline{3}$ & 1 (2\%). & 1 (2\%). & \\
\hline Street/Van Outreach & $\underline{7}(\underline{14 \%})$. & $\underline{4}(\underline{8 \%})$. & - \\
\hline
\end{tabular}

Table 2: Impact of SARS-CoV-2 pandemic on operations and infection control for HR sites 


\begin{tabular}{|ll|}
\hline \multicolumn{2}{|l|}{ March-May 2020 } \\
\hline Management/Operations at Independent HR Sites ${ }^{\text {a }}$ \\
\hline Decreased Hours & $4 / 10(40 \%)$ \\
\hline Decreased Budget & $5 / 10(50 \%)$ \\
\hline Supply Shortages & $8 / 10(80 \%)$ \\
\hline Reduced Services & $5 / 10(50 \%)$ \\
\hline Increased donations to clients ${ }^{\text {b }}$ & $6 / 10(60 \%)$ \\
\hline Infection Control at all Open Sites ${ }^{c}$ & \\
\hline Physical Distancing & $48 / 48(100 \%)$ \\
\hline Increased Sanitation & $47 / 48(98 \%)$ \\
\hline PPE Requirements & $46 / 48(96 \%)$ \\
\hline Symptom Screening, staff & $41 / 48(85 \%)$ \\
\hline Symptom Screening, clients & $42 / 48(88 \%)$ \\
\hline Temperature Screening, staff & $41 / 48(85 \%)$ \\
\hline Temperature Screening, clients & $3 / 48(6 \%)$ \\
\hline
\end{tabular}

a- Management and operations changes reported by independently-operated sites that remained open $(\mathrm{N}=10), 2$ sites closed completely and are not included.

b- Donations included cloth masks, hand sanitizer, food, telemedicine buprenorphine

c- Infection control changes reported by all sites that remained open during the pandemic $(\mathrm{N}=48)$

Table 3: Reported changes in substance use community experience during the SARS-CoV-2 pandemic 


\begin{tabular}{|ll|}
\hline & March-May 2020 \\
\hline Respondents $^{\text {a }}$ & 13 \\
\hline Illicit Drug Scarcity & $2(15 \%)$ \\
\hline Illicit Drug Price Increases & $3(23 \%)$ \\
\hline Increased Opioid Withdrawal & $1(8 \%)$ \\
\hline Increased Alcohol Withdrawal & $1(8 \%)$ \\
\hline Increased Drug Overdose Death & $1(8 \%)$ \\
\hline
\end{tabular}

a- Survey respondents (12 independent and $1 \mathrm{DOH}$ )

\section{Supplementary Files}

This is a list of supplementary files associated with this preprint. Click to download.

- AppendixA.docx 